\title{
Professional Stress Factor of Vulnerability in Which Has Occurred of the Road Traffic Accidents at a Sample of Drivers in Morocco
}

\author{
I. Echerbaoui' ${ }^{1}$ I. Cherkaoui El Malki', A. O. T. Ahami' ${ }^{1}$ C. Mottier ${ }^{2}$, P. Wallon ${ }^{3}$ \\ ${ }^{1}$ Équipe de Neurosciences Cognitivo-Comportementale \& Santé Nutritionnelle, Département de Biologie, \\ Faculté des Sciences, Université Ibn Tofail, Kénitra, Maroc \\ ${ }^{2}$ Sélection \& Conseils, Nyon, Suisse \\ ${ }^{3}$ Chargé de recherche INSERM Saint Rémy lès Chevreuse, France \\ Email: damilife@gmail.com
}

How to cite this paper: Echerbaoui, I., Cherkaoui, E.I., Ahami, A.O.T., Mottier, C. and Wallon, P. (2017) Professional Stress Factor of Vulnerability in Which Has Occurred of the Road Traffic Accidents at a Sample of Drivers in Morocco. Open Journal of Medical Psychology, 6, 213-227. https://doi.org/10.4236/ojmp.2017.64017

Received: July 20, 2017

Accepted: August 26, 2017

Published: August 29, 2017

Copyright $\odot 2017$ by authors and Scientific Research Publishing Inc. This work is licensed under the Creative Commons Attribution International License (CC BY 4.0).

http://creativecommons.org/licenses/by/4.0/ (c) (i) Open Access

\begin{abstract}
The professional stress is a physical and emotional harmful reaction. In fact, it presents a major public health problem in Morocco. Our work is directed to study the differences between the various groups of professional and nonprofessional drivers in terms of stress reactions, noise nuisance and implication in the production accidents. The present study is transversal descriptive type based on a questionnaire and neuropsychological tests conducted by 60 nonprofessional drivers and 60 taxi drivers in Kenitra. Two scales evaluated the stress: the Resistance Test of Stress (TRS) and the Perceived Stress Scale (PSS). According to this last scale, $63.5 \%$ of the taxi drivers were considered as stressed. These drivers have the following specific components: mood trouble, sleep trouble, pressure of time, work boredom, stress sensation and tiredness at the end of driving. $65 \%$ of drivers take a pause after 5 to 6 hours of work. According to the Test of Resistance at the Stress, the taxi driver's populations are more homogeneous but are less likely to resist stress compared to their nonprofessionals counterparts. Indeed to work on the professional stress requires a qualitative and quantitative approach phenomenon allowing a more complete vision. This study sheds new light on the understanding of stress at work by using new measurement and evaluation methods such as TRS, with an aim to reduce or to eliminate the number of road accident.
\end{abstract}

\section{Keywords}

Professional Stress, Morocco, Noise Nuisance, Accident, Resistance Test of Stress 


\section{Introduction}

The stress is a phenomenon which is natural and essential to the survival of each one of us and who affects almost everyone allowing the individual to adapt to situations changing. Occupational stress exists in all companies. Several researchers often define the stress as the response of the body in any request, which exceeds the capacity of adaptation of the individuals [1]. Whereas former studies highlighted the multidimensional nature of stress during control [2] [3]. In this connection, the stress was shown to have an obvious impact on the various cognitive components of the performances sensorimotor [4]. Although the harmful effects caused by the problems of health induced by the stress were identified, the method of adequate measurement of the professional stress at the drivers is dubious. With the difference of the body mass index (BMI) or arterial pressure (AP), which can be measured objectively, the effect of the stressing events is partially determined by people perceptions of their own feeling [5]. The researchers have varied views on the etiology of the professional stress. The cognitive neuroscience showed that the stress hormones affect the brain (Prefrontal lobe) and the dopaminergic ways [6] [7]. Studies primarily treat physiological stress reactions during the execution of the control spot and the existing bonds between the road accidents and the scores on stress scales of the daily life [8]. Generally speaking, these results show an improvement on the driver's physiological reactions [9] and more precisely on road congestion.

Indeed, professional drivers (PD) are confronted with multiple exposures, which are sometimes harmful for their health such as the noise, which represents a very widespread harmful effect on the control environment. Professionals are subjected to noise in the majority of industry branches, including transport services. And as a cofactor of stress, noise can also involve harmful effects on health, and it is shown that a permanent or intermittent sound aggression can meet in airports vicinities or motorways, sound also increases the risk of arterial hypertension [10]; myocardial infarctions [11] and neuroendocrine disorders [12] were reported, with a high secretion of certain neurotransmitters like the noradrenergic one and the ACTH.

It is also admitted that sleep is disturbed if ambient noise exceeds $45 \mathrm{~dB}$ for European Community, while $35 \mathrm{~dB}$ for the World Health Organization [13]. Moreover, the daily exposure to noise strong levels can worsen the effects of noise on man and entrained an additive tiredness, hearing impairments and even professional deafness [14] [15].

\section{Stress, road safety and taxi drivers (TD) work regulation}

Stress is very often presented within professional life framework. It is the main cause of problems and constraints of general health for professional drivers such as small taxis drivers since they are directly related to public safety. Taxi drivers (TD or PD) spend the majority of their time on roads. This could explain their predominance of road knowledge and cognitive qualifications, which are more developed than non-professional drivers (NPD). They are an essential part of 
transport public system [16]. They are recognized as a special group with specific behavioral characteristics [17], but this later is among the most dangerous trades because many implied risks [18] [19] claim that taxi drivers prefer to drive in excessive speeds and change lanes carelessly.

Concerning Moroccan taxi driver's regulation, it presents a certain number of gaps, which relates primiraly to medical cover, work schedules, retirement, wages, social security etc., and this state caused an absence of organization in their work, which generates several driver disorders, which is behavioral, cognitive or psychological, and especially generators of stress state and insecurity.

This study aim was to study the differences between the various groups of professional drivers and non-professionals in terms of stress reactions, sound harmful effects and implication in the production of road accidents.

\section{Method}

The study was carried out in Kenitra town on a surface of $76 \mathrm{~km}^{2}$; it is the fourth industrial town of the country, in West North of Morocco, with more than one million inhabitants.

Our study was of a transversal type with a descriptive and an analytical aim. It was held on March 2017.

\subsection{Participants}

Hundred twenty subjects of male sex were selected by a simple random sample for the needs for the experimentation and were divided into two groups of sixty subjects: a group made up of non-professional drivers and a group of professional ones (taxi drivers). The non-professionals were 28 to 52 years old ( $\mathrm{M}=$ 41.83; SD = 5.03) with an experiment of higher control than 5 years. The tested drivers were 30 to 55 years old $(M=41.87$; $\mathrm{SD}=6.27)$ more than half of these drivers run through 13,000 kilometers at least per year and worked like taxi drivers at least for more than 7 years Table 1.

The non-professional drivers study level is heterogeneous: 16 (26.66\%) of them have the baccalaureate level, 7 (11.67\%) pursued their higher education and 37 (62.66\%) made short studies (Primary, junior higher school/high school). However, the study level of the professional drivers is more homogeneous: 18 (30\%) of them have the baccalaureate level, 30 (50\%) made short studies (junior higher school/high school) and 12 (20\%) continued their higher studies Table 1.

The same methods of recruitment were used to recruit the various groups of participant drivers in order to eliminate possible skew from sampling. 8\% of the total population (760) of Kenitra town taxi drivers contributed to this study.

Participants were informed of the anonymity of the study, its interest and the possibility of refusing to participate. For ethical considerations, the survey was carried out only after the official agreement of the subjects. 
Table 1. Descriptive statistics.

\begin{tabular}{|c|c|c|c|c|c|c|}
\hline & \multirow{2}{*}{\multicolumn{2}{|c|}{$\begin{array}{c}\mathrm{PD} \\
\mathrm{N}=60(50 \%)\end{array}$}} & \multirow{2}{*}{\multicolumn{2}{|c|}{$\begin{array}{c}\text { NPD } \\
\mathrm{N}=60(50 \%)\end{array}$}} & \multirow{3}{*}{$x^{2}$} & \multirow{3}{*}{$p$} \\
\hline & & & & & & \\
\hline & M & SD & M & $\mathrm{SD}$ & & \\
\hline \multirow[t]{2}{*}{ Age } & 41.87 & 6.27 & 41.83 & 5.03 & & \\
\hline & $\mathrm{N}$ & $\%$ & $\mathrm{~N}$ & $\%$ & & \\
\hline Driver's license (or years of seniority) & & & & & $22.051^{\star}$ & $0.001^{\star}$ \\
\hline$>18$ years & 15 & 25 & 0 & 0 & & \\
\hline$>11$ years & 27 & 45 & 25 & 41.66 & & \\
\hline 11 years $>A>7$ years & 18 & 30 & 35 & 58.33 & & \\
\hline Level of study & & & & & 1.845 & 0.398 \\
\hline Studies primary education & 19 & 31.66 & 19 & 31.66 & & \\
\hline Collegial studies or secondary & 28 & 46.66 & 22 & 36.66 & & \\
\hline Higher studies & 13 & 21.66 & 19 & 31.66 & & \\
\hline Matrimonial statute & & & & & 2.733 & 0.435 \\
\hline Single & 5 & 8.33 & 10 & 16.66 & & \\
\hline Married & 48 & 80 & 42 & 70 & & \\
\hline Divorced & 5 & 8.33 & 7 & 11.66 & & \\
\hline Widowers & 2 & 3.33 & 1 & 1.66 & & \\
\hline
\end{tabular}

PD: professional drivers; NPD: non-professionals drivers; ${ }^{\star} p<0.001$.

\subsection{Measures}

It was carried out by means of a questionnaire, called computerized test: Test of Resistance to Stress (TRS), and of a scale known as Perceived Stress Scale 10 (PSS-10).

\subsubsection{Questionnaire}

The questionnaire relating to the data gathering on the participants comprised two aspects with 41 items:

1) The first shutter made its best to record general information of the subjects (age, sex, matrimonial statute, professional, educational level) and of information on the general health.

2) The second shutter was based on the use characteristics of car: the history of the subject as a driver, its practices of control and its behaviors (infringements, errors, strategies of optimization) like its opinion on its driver capacities.

\subsubsection{Test Resistance to Stress (TRS)}

This test was initially created by André Rey, under the name of "Test of the organized points"; it was then about an aptitude test Visio-space, without any allusion with the emotion. It was about a test of spatial organization, a basic test in the vocational guidance, Charles Mottier used during a score of years. In 2011, an automated version was developed, in co-operation with Seldage [20] [21]. It was then a question of constituting 15 lines of 6 boxes, including understanding each one two squares and a triangle. Thanks to data-processing program, the 
boxes were made up, so that in each line, the boxes present an increasing difficulty.

The subject has 40 seconds per line, at the end of what it must change line. It operates while clicking with the mouse on the points to connect them. When it connected three points for a square, this one is finished automatically. The test lasts on the whole 10 minutes.

The stress is consisted of a sound track that the subject perceives through earphones. Each line has a clean sound sequence.

The first five sequences are regarded as not-stressing, the five following ones represent moderated stresses, the five last of the severe stresses because bringing into play vital experiments (noise of hearth, smothering...).

\subsubsection{Perceived Stress Scale (PSS-10)}

The Perceived Stress Scale (PSS) is a classic stress assessment instrument. PSS-10 is a unidimensional scale which evaluates the perceived stress. It evaluates the state of stress perceived (feeling of control: evaluate the frequency with which the situations of the life (or work) are general lies perceived like threatening) [5], [22]. The PSS has a good discriminating validity [23].

Concerning the sex, there is no significant difference between the men and the women. The subject estimates its frequency of appearance over one recent period (the past month) in a frequency of 5 points (of "never" in "very often") on a scale from Likert with $0=$ never, $1=$ almost never, 2 = sometimes, 3 = rather often, and $4=$ very often. The items 4, 5, 6, 7, 9, 10 and 13 are opposite.

\subsection{Procedures}

The administration of the questionnaire and the tests was made in the principal taxi ranks distributed on all the town of Kenitra, and at the time when the drivers awaited their turn or with coffees where the drivers were replaced with their colleagues.

In the majority of the cases, the answers were collected during a maintenance and, if need be, certain questions were explained in terms simple and accessible to all (in dialectical Arabic). One excluded the subjects not being accustomed to using a computer to ensure a good administration of the test computerized TRS.

\subsection{Statistical Analysis}

Coding, the processing and the statistical analysis data were made with SPSS V.20. The statistical tests used were Khi2 and ANOVA. A $p<0.05$ was considered statistically significant.

\section{Results}

\subsection{Descriptive Statistics}

The average age of taxi drivers was $41.87 \pm 6.27$ years and $41.83 \pm 5.03$ years for non-professional drivers. The average seniority at work for the taxi drivers was: 
$25 \%$ of the drivers have more than 18 years of seniority, $45 \%$ of the drivers have a seniority of more than 11 years and $30 \%$ of the drivers have a seniority of more than 7 years and less than 11 years. However, the average seniority of the driving license of non-professional drivers was of: $58.3 \%$ of the drivers have a seniority higher than 11 and $41.7 \%$ of the drivers have a seniority higher than 7 years and less than 11 years. Regarding the marital status, $80 \%$ of the taxi drivers are married, $8.33 \%$ are single, $8.33 \%$ are divorced and $3.33 \%$ widowers. On the other hand, $70 \%$ of the non-professional drivers are married, $16.66 \%$ are unmarried, $11.66 \%$ are divorced, and $1.66 \%$ are widowers. The level of education is good overall for all of the two groups, but heterogeneous as well. $21.66 \%$ of the taxi drivers followed their higher studies, $46.66 \%$ have received secondary or high school education and $31.66 \%$ of them have only completed primary education.

However, the level of education of the non-professional drivers is more homogeneous, $31.66 \%$ of them followed their higher studies, $31.66 \%$ did not exceed the primary education and $36.66 \%$ attended secondary or high school levels $\mathrm{Ta}$ ble 1 .

\subsection{Perceived Health and Medical History}

The questionnaire also allowed to analyze the perception of the individuals on their health conditions in order to see whether this has an influence on their driving performance. The results showed that $91.7 \%$ of the interviewed taxi drivers said to have good to better health, with $18 \%$ suffering from sight problems. Almost half of the respondents reported smoking and $1 / 3$ of them are alcoholic.

However, approximately $77 \%$ of the non-professional drivers said to have good to better health and $23.3 \%$ with bad health; $15 \%$ suffered from sight problems: $18.3 \%$ of the drivers reported smoking and $10 \%$ of them are Alcoholic. Thus, the majority of the drivers do not have Hearing problems (PD: $98.3 \%$; NPD: 95\%).

\subsection{Disorders Generating a State of Stress}

$13.3 \%$ of the interviewed Taxi drivers stated to have difficulties of drowsiness, $15 \%$ of restless nights; $25 \%$ of insomnia and $30 \%$ of parasomnias, against $8.3 \%$ of the interviewed non-professional drivers who said to have difficulties of sleepiness; $16.7 \%$ of insomnia and $5 \%$ of parasomnias. Concerning stress disorders: $60 \%$ of the taxi drivers stated to have the feeling of being ill at ease and having headaches. Approximately $32 \%$ with a feeling of tension and $8,3 \%$ with a tremor of extremities; against $21.7 \%$ of the CNP with the feeling of being ill at ease and having headaches. About $23.5 \%$ with a feeling of tension and $8.3 \%$ suffering from a tremor of the ends Table 2.

Symptoms of anxiety and irritability were reported by approximately $55 \%$ of the drivers and $20.7 \%$ among them are discouraged. However, approximately 
Table 2. Prevalence of various symptoms evoking a state of stress.

\begin{tabular}{|c|c|c|c|c|c|}
\hline & & $\mathrm{PD}$ & NPD & \multirow{2}{*}{$x^{2}$} & \multirow{2}{*}{$p$} \\
\hline & & $\%$ & $\%$ & & \\
\hline \multirow{5}{*}{ Sleep disorders } & Insomnia & 25,0 & 16,7 & \multirow{5}{*}{3.592} & \multirow{5}{*}{$0.30 s$} \\
\hline & Parasomnias & 30,0 & 5 & & \\
\hline & Difficulties of drowsiness & 13.3 & 8.3 & & \\
\hline & Restless nights & 15.0 & 0 & & \\
\hline & No sign & 16.7 & 70 & & \\
\hline \multirow{4}{*}{ Disorders of tension } & Feeling of tension & 31.7 & 23,3 & \multirow{4}{*}{$21.053^{\star *}$} & \multirow{4}{*}{0.000} \\
\hline & Feeling to be badly at ease & 26.7 & 10 & & \\
\hline & Tremor of extremities & 8.3 & 8.3 & & \\
\hline & Headaches & 33.3 & 11.7 & & \\
\hline \multirow{4}{*}{ Disorders of mood } & Anxiety & 46.7 & 15 & \multirow{4}{*}{$29.357^{* *}$} & \multirow{4}{*}{0.000} \\
\hline & Irritability & 8.3 & 15 & & \\
\hline & Discouragement & 20.7 & 1.7 & & \\
\hline & No sign & 24.3 & 68.3 & & \\
\hline Cognitive symptoms & $\begin{array}{c}\text { Difficulty of maintaining the } \\
\text { quality of work }\end{array}$ & 56.7 & 6.7 & $34.660^{* *}$ & 0.000 \\
\hline
\end{tabular}

PD: professional drivers; NPD: non-professionals drivers; ${ }^{* *} p<0.000$.

$30 \%$ of the CNP and $1.7 \%$ of them are discouraged. Thus, the difficulty of maintaining the quality of work was reported at $57 \%$ of the PD; and of $6.7 \%$ of CNP with NPD Table 2.

The $\chi^{2}$ test revealed a significant difference between the two groups of drivers: tension disorders $\left(\chi^{2}=21.053, p<0.000\right)$, mood disorders $\left(\chi^{2}=29.357, p<\right.$ $0.000)$ and the difficulty in maintaining the quality of work $\left(\chi^{2}=34.660, p<\right.$ $0.000)$.

\subsection{Perception of the Working Conditions of the Taxi Drivers}

The drivers of the small taxis worked 8 to 12 hours per day and $66.7 \%$ of the drivers travelled on average $200 \mathrm{~km} .43 .3 \%$ of the overall drivers worked during the night. Eight drivers out of ten were not owners of their taxis and $93.3 \%$ did not have other trades. $18.3 \%$ of the taxi drivers said to have driven through the red light and more than one third did not respect prohibitions against a very low percentage of NPD. Thus, $53.3 \%$ of the interviewed taxi drivers stated to have used the cellphones while driving, the majority (63.3\%) felt stressed upon hearing the whistle of the police officer and $66.6 \%$ became fatigued while driving, against $65 \%$ of the non-professional drivers who said to have used the cellphones while driving, the whistle of the policeman caused stress to half of them while driving and $30 \%$ became fatigued during driving

There was a significant difference between the increase in the number of accidents during the telephone conversation during driving $\left(\chi^{2}=16.900, p<0.001\right)$ 
and the police whistle $\left(\chi^{2}=17.079, p<0.000\right)$.

Thus, taking the required break is necessary for drivers at work. In that regard, $65 \%$ of the taxi drivers said to have taken the break time after 5 to 6 working hours, and about $23.5 \%$ among them take rest after 4 hours working time, whereas for a low proportion of them take rest after 2 to 3 hours of work (11.5\%). The $\chi^{2}$ test showed a significant difference between taking the break and producing road accidents among taxi drivers $\left(\chi^{2}=10.207, p<0.046\right)$.

\subsection{Scale of Perceived Stress}

Figure 1 shows the various states of stress encountered by the two groups of drivers: Taxi drivers: a little more than two-thirds (63.33\%) of the drivers suffer from a regular stress if not to say chronic, however, $18.33 \%$ suffer from an irregular stress and light stress. The analysis of variance ANOVA enabled us to put forward a significant difference between the score of the scale of perceived stress (PSS) and different characteristics: The boredom in their work ( $\mathrm{F}=14.184, p<$ $0.001)$, The sound of the whistle of the policeman $(\mathrm{F}=6.504, p<0.003)$, The use of the cellphones during driving $(\mathrm{F}=24.375, p<0.001)$, The Accidents of the public road $(\mathrm{F}=8.878, p<0.001)$, and Time pressure throughout during driving time $(\mathrm{F}=16.557, p<0.001)$.

Approximately $24 \%$ of the $\mathrm{CP}$ suffer from a regular stress if not chronic, $30 \%$ of them with irregular stress and $46.5 \%$ with light stress. According to the ANOVA, one observed significant differences between the score of PSS and different characteristics: The level of study of the drivers ( $\mathrm{F}=5.632, p<0.006)$, Disorders of sleep $(\mathrm{F}=12.301, p<0.001)$, Disorders of $\operatorname{mood}(\mathrm{F}=13.000, p<$ $0.001)$, The sound of the whistle of the policeman ( $\mathrm{F}=87.908, p<0.001)$, The use of cellphones during driving $(\mathrm{F}=33.802, p<0.001)$, The traffic noise $(\mathrm{F}=$ $36.879, p<0.001)$, Accidents occurrence in the public road $(\mathrm{F}=6.623, p<$ $0.002)$.

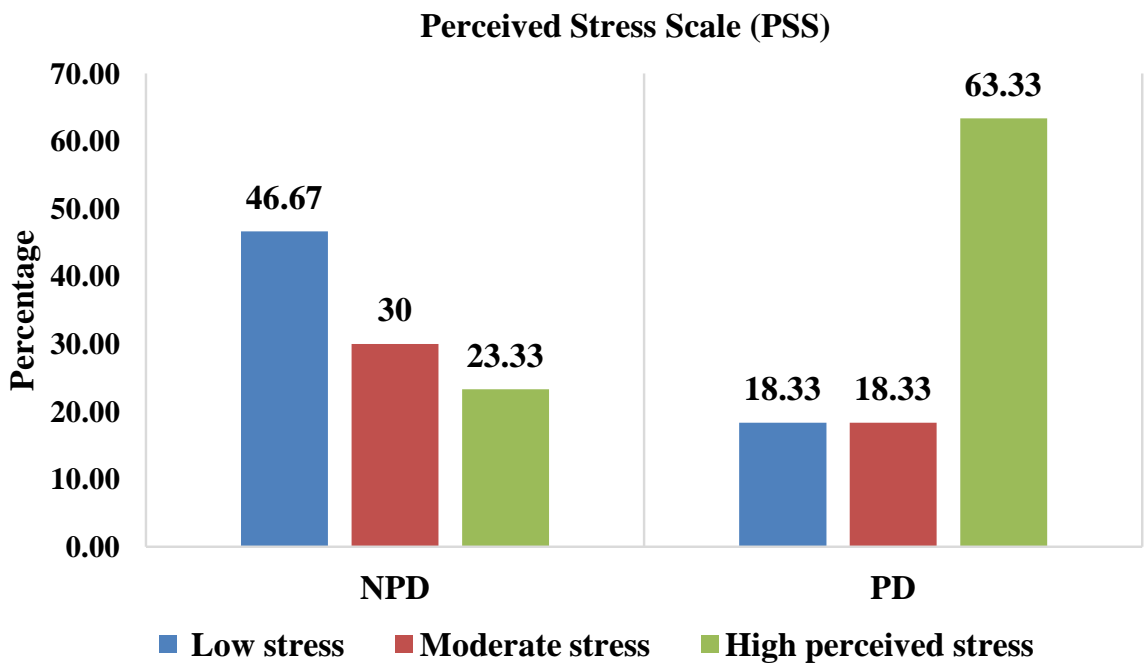

Figure 1. Prevalence of the different states of stress in the two groups of drivers. 


\subsection{Test Resistance to Stress (TRS)}

\subsubsection{Stressful Stimuli According to the Number of Successful Boxes}

Figure 2 presents 15 various stressing sound stimuli used in the Resistance Test to Stresses, ranged from 1 to 15: The first five sequences are regarded as not stressing, the five following ones represent moderated stresses, the last five of the severe stresses because of involving vital experiments.

The taxi drivers are resistant to the various stressors; of the highest scores of successful boxes: OM (228), SMOTHERING (228), MUSIC MOD (203), INSECTS (201), RATES/RHYTHMS AFRICAN (199), WAGNER (175), PERCUSSIONS (167), LOUPS (161), CHILDBIRTH (156), STORM (147), AMBULANCE (147), ACCIDENT OF the CAR (146), HEART (143), with least low score of the correct boxes: CRIES OF NEWBORNS (140).

The non-professional drivers are also resistant to the various stressors; highest scores of successful boxes: OM (225), SUFFOCATION (219), INSECTS (210), MOD MUSIC (207), RATES/AFRICAN RHYTHMS (202), WAGNER (192), WOLVES (180), PERCUSSIONS (178), CAR ACCIDENTS (175), STORM (170), CHILDBIRTH (159), PANIC (156), AMBULANCE (153), HEART (145), to the least low score of the correct boxes: CRIES OF NEWBORNS (144).

Figure 2 presents the degrees of resistance to the stress according to the type of drivers.

Taxi drivers: One notes that $15 \%$ of the drivers have a good resistance to the stress; approximately $67 \%$ have a moderate level of resistance, while $18.33 \%$ have a low resistance to the stress.

Non-professional drivers: Approximately $17 \%$ of the Drivers have a good resistance to the stress, $70 \%$ with a moderate level of resistance and $13.33 \%$ have a low resistance to the stress.

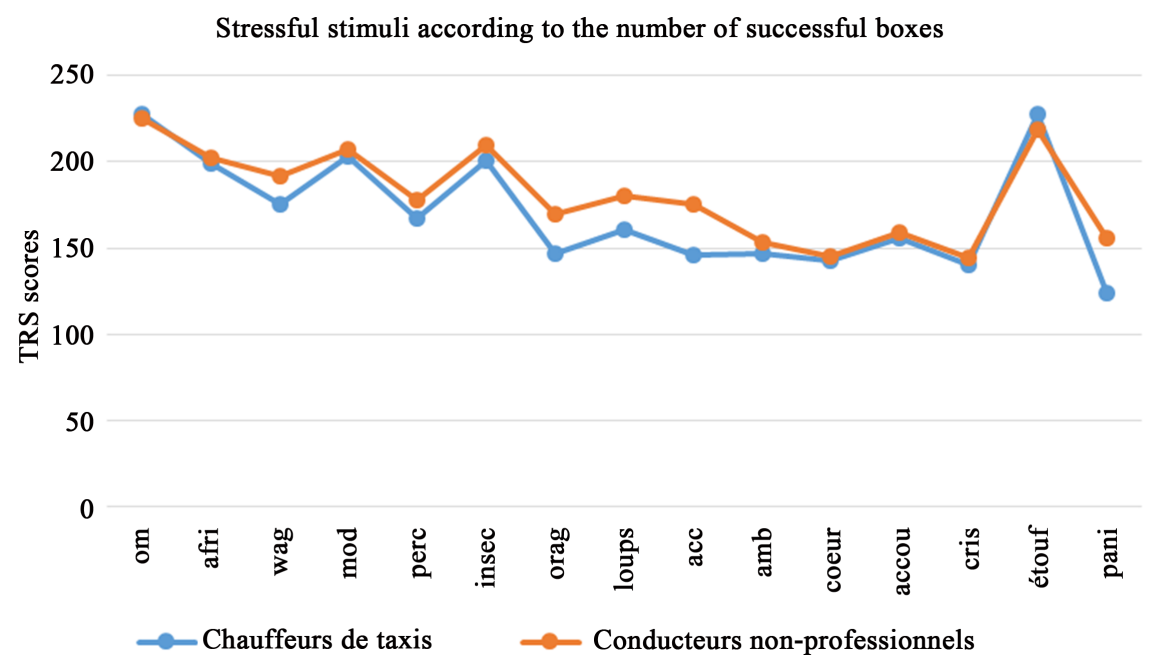

Figure 2. Representation of the means of the successful boxes according to the type of the sound stimuli. Om: OM; Afri: Rythmes Africains; Wag: Wagner; Mod: Musique Mod; Perc: Percussions; Insec: Insectes; Orag: Orage; Loups: Loups; Acc: Accident des voiture; Amb: Ambulance; Cœur: Cœur; Accou: Accouchement; Cris: Cris nx-nes; Étouf: Etouffement; Pani: Panique. 
There is no significant difference between the two populations $(\mathrm{R}=-0.025, p$ $=0.947$ ), but a slight superiority of the non-professional drivers who show less extreme results (standard deviation).

The performances of driving decrease progressively with the stressors, except for the smothering phase.

The population of the taxi drivers is more homogeneous but offers less resistance to the stresses than the non-professional drivers.

\subsubsection{Stress and Accidents of the Public Road}

Figure 3, on the other hand, shows that the drivers having undergone only one accident have an average score of resistance to the stress (average resistance), the drivers who did not undergo accidents have a high score (good resistance) while those who have a weak score underwent two accidents (low resistance).

The figure below presents the score of the test resistance to the stress in relation to the occurrence of the accidents.

The analysis of variance (ANOVA) enabled us to propose a significant difference between the occurrence of accidents of the public road and some sound stimuli used in the Test Resistance to the Stress:

Taxi drivers: OM $(\mathrm{F}=5.736, p<0.005)$, AFRICAN RATES/RHYTHMS $(\mathrm{F}=$ $9.011 p<0.001)$, WAGNER $(\mathrm{F}=5.318, p<0.008)$, MUSIC MOD $(\mathrm{F}=4.191, p<$ $0.020)$, PERCUSSIONS ( $\mathrm{F}=4.467, p<0.016)$, INSECTS $(\mathrm{F}=10.615, p<0.001)$, STORM ( $\mathrm{F}=3.196, p<0.048)$, WOLVES $(\mathrm{F}=7.674, p<0.001)$, CARS ACCIDENTS $(\mathrm{F}=3.295, p<0.044)$, CHILDBIRTH $(\mathrm{F}=9.323, p<0.001)$. In addition, CRIES OF NEWBORNS $(\mathrm{F}=8.582, p<0.001)$.

Non-professional Drivers: CHILDBIRTH ( $\mathrm{F}=4.062, p<0.022)$, CRIES OF NEWBORNS $(\mathrm{F}=3.645, p<0.032)$.

However, there is no significant difference between the accidents of the public road and the other stimuli sound.

Stress and accidents of the public road

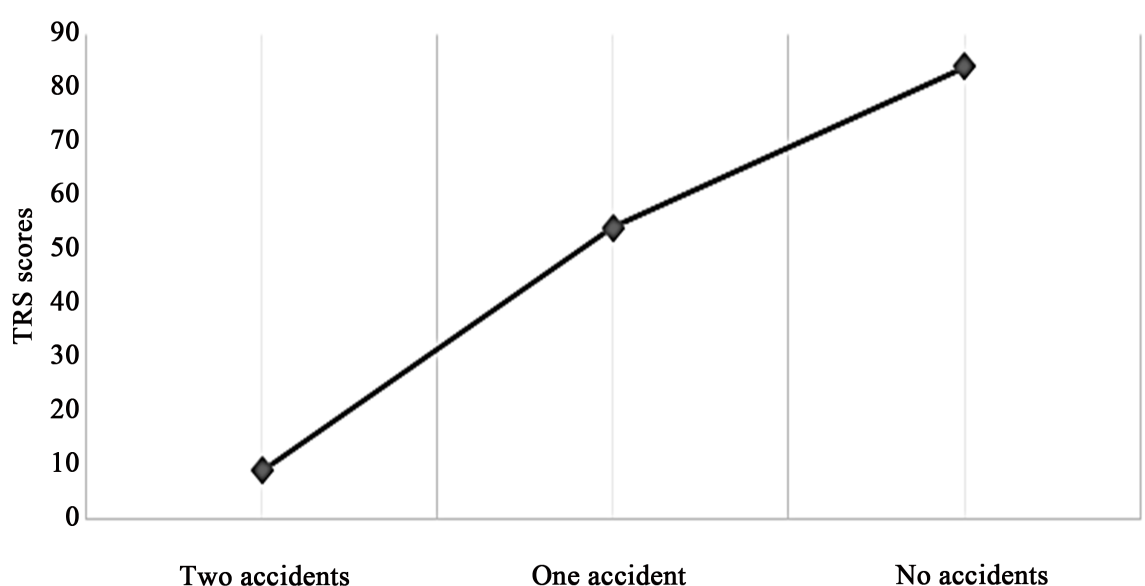

Figure 3. Relationship between TRS scores and accidents of the public road 


\section{Discussion}

The study showed that the level of stress is relatively high in this professional category of drivers compared to non-professional drivers. One can also note that the study, in spite of the fact that it is transverse and cannot claim to show a causality, allowed the description of a certain number of factors associated with this stress, like the boredom in their work, the feeling of the absence of safety, the noise of the traffic, the sound of the whistle of the policeman, the use of cellphones during driving, the occurrence of accidents in the public road, time pressure during driving, making a break, the level of study of the drivers, the disorders of sleep, the disorders of mood and the disorders of tension.

It should also be noted that few studies were interested in the evaluation of the professional stress of the population of the taxi drivers [24] and according to the literature, no Moroccan study treated the effects of sound pollution like generating factor of the professional stress.

\section{Organization of the Taxi Drivers' Work}

It is known that the professional stress is related to the type of activity and the organization of work. In the forefront of the announced factors as generators of stress, the time constraints appear. This concept covers the feeling which the individual has when working under pressure of time and to have to carry out too much work within a too short time [25]. In this study $78.3 \%$ of the drivers said to feel a pressure of time and $53 \%$ state not to have time necessary to work. These results also joined those of a study carried out in Japan on taxi drivers who showed that the concern of the drivers as for their daily profit increased the level of the stress and had effects on the quality of work [26]. This situation involves competitions between the taxis with harmful consequences as regards to road safety [27].

The driving of the taxis is monotonous and repetitive, inducing trouble, a lack of motivation and dissatisfaction. These feelings of boredom in work were reported by $83.3 \%$ of the drivers of our study. This observation joined a study undertaken about the workers of an assembly line in the USA showed similar results to ours [28].

Another factor is determining and is essential to the work of the drivers, it is the break time. In this connection, $65 \%$ of the taxi drivers said to have taken a break after 5 to $6 \mathrm{~h}$ of work. In this work one could propose a significant difference between taking a break and the score of the scale of stress perceived (PSS), and one noticed that the increase in the score of the stress requires an increase in the hours before the break time.

Difficult working conditions also were often associated with the professional stress. In this study, the difficulty of maintaining the quality of work was reported in $57 \%$ of the cases, and the feeling of insecurity because of the absence of social security was noted at $68.3 \%$ of the drivers. The fear of losing its job is also likely to increase the psychological tension of the drivers. It is obvious that the choice of the profession, the job satisfaction and the possibility of decision con- 
stitute factors significantly protective against the stress [29]. At the international level, during these ten last years, several countries set up programs of information of group bound for the drivers or taxi drivers within the framework of action plans on the road safety (the United States, Canada). However, Morocco until now did not develop its vision on the information and application actions in the field of the road safety in the objective of decreasing the road accidents.

\section{Test Resistance to the Stress}

As it was to evoke in methodology, it acts of an automated test of Swiss origin and let us have to apply it on the Moroccan Arabic-speaking population close the occupational drivers (taxi drivers) and non- professionals. Test A was carried out for the first time in Morocco on the drivers that are professional (PD) or not professional in order to provide to the professionals of transport to work on economic and reliable tool to evaluate their resistance to the stress.

A first version paper-pencil with additive stimuli was validated on various populations of candidates to ancillary medical formations. The results obtained confirmed deduction of this technique and justified, in collaboration with Philippe Wallon, a computerized application [20]. Let us recall that the first objective this TRS is initially to measure resistance to the stress from the drivers and then to rise the most frequent anomalies or dysfunctions at the non-professional or professional drivers and to propose remedy in order to prevent the public road accidents and to maintain the quality of professional driver's lives.

\section{Analyze Sound Stimuli}

The test is based on a corpus of 15 additive stimuli used as stressors under conventional names: OM, AFRICAN RATES/RHYTHMS, WAGNER, MUSIC MOD, PERCUSSIONS, INSECTS, STORM, WOLVES, ACCIDENT OF THE CAR, AMBULANCE, HEART, CHILDBIRTH, CRIES OF NEWBORNS, SMOTHERING and PANIC.

According to the TRS, the population of the taxi drivers is more homogeneous but offers a resistance to the stresses a little weaker than the non-professionals drivers. This aspect of variable resistors towards the sound stimuli of the TRS can be explained, on the professional drivers, by the continuous exposure on high levels of harmful sound effect and noise during their work. Moreover, the literature identified the negative impact of the distractions during driving such as the music, the noise of the traffic, the conversation during driving, to telephone while leading, etc. [6] [29]. Cohen (1983) also mentioned the effects of the noise to work on the productivity, safety, the performance, the mental conscience and vigilance [5].

In this study, one notes that the noise of the traffic is more stressing at almost half of the nonprofessional drivers and less stressing at the professional drivers (18\%) seen in continuous exposure which carries out towards the adaptation to the noise. However, the noise represented by the whistle of the policeman is more stressing for the drivers (64\% of the drivers feel it), that can be explained by the fact why it represents a sanction occurring following a transgression of 
the highway code and law. Moreover, one also notes a significant difference between the score of the PSS and the whistle of the policeman, on the two populations of drivers. However, no significant difference is observed between the sound of the noise of the traffic and the score of the PSS on the taxi drivers.

\section{Perceived Stress Scale}

The PSS is a scale which evaluates the frequency with which the situations of the life (or work) are generally perceived like threatening (perceived control). Willams (2000) observed a relation between the perceived stress measured by the PSS, the job satisfaction and physical and mental health [30]. Thus Chang (1998)

[31] found that the PSS are associated symptoms of depression and the satisfaction of life. In this study one proposed a significant difference between the score of the scale of stress perceived (PSS) and the trouble in their work, of the public road accidents and the pressure of time during driving of the taxi drivers. The stress decreases the performance, when it intense or is prolonged too much, because all the cognitive functions of the individual are then disturbed [32]. In this study one could propose a significant difference between the two populations concerning the performances of driving which decrease progressively with the stressors (auditive stimuli of test TRS) with a light superiority of the non-professionals drivers. To date, there are no studies which explored the bond between the safety of driving and the stress in Morocco. Moreover, one observed significant differences between score PSS and the disorders of sleep, the disorders of mood, the disorders of tension, the sound of the whistle of the policeman, the noise of the traffic, and the occurrence of the accidents in the public road, on the non-professional drivers.

Indeed, the accidents of the public road constitute today a major social problem in Morocco. In this work, one observes a significant difference between the occurrence of accidents in the public road and the score of PSS, the score of the TRS and the feeling of the absence of safety during driving: $33.3 \%$ of the taxi drivers state to have had only one accident as a driver and $11.7 \%$ had two accidents of it; However, $18.3 \%$ of the non-professional drivers said to have had only one accident as drivers, $13.3 \%$ of them had two accidents.

\section{Conclusion and Prospects}

At the end of this work, we could highlight the factors of perceived professional stress which is specific to the trades of taxi drivers. Indeed, the latter brought a new enlightenment to the understanding of the stress at work by using new methods of measurement and evaluations such as the TRS. We tried in our work to identify, evaluate and describe the consequences of the stress related to the professional environment of the taxi drivers, and to highlight the bonds between the profiles of drivers and those of the occupational stress in order to reduce the accidents due to the stress and thus to improve the quality of life of this category of drivers. This study helps to develop measurements of prevention with an aim of reducing or of eliminating the sources of the stress at work. 


\section{Acknowledgements}

The authors thank all those who contributed closely or by far to the realization

of this work.

\section{References}

[1] Selye, H. (1936) A Syndrome Produced by Diverse Nocuous Agents. Nature, 138, 32. https://doi.org/10.1038/138032a0

[2] Gulian, E., Matthews, G., Glendon, A.I., Davies, D.R. and Debney, L.M. (1989) Dimensions of Driver Stress. Ergonomics, 32, 585-602.

https://doi.org/10.1080/00140138908966134

[3] Öz, B., Özkan, T. and Lajunen, T. (2010) Professional and Non-Professional Drivers' Stress Reactions and Risky Driving. Transportation Research Part F: Traffic Psychology and Behaviour, 13, 32-40. https://doi.org/10.1016/j.trf.2009.10.001

[4] van Galen, G.P. and van Huygevoort, M. (2000) Error, Stress and the Role of Neuromotor Noise in Space Oriented Behaviour. Biological Psychology, 51, 151-171. https://doi.org/10.1016/S0301-0511(99)00037-X

[5] Cohen, S., Kamarck, T. and Mermelstein, R. (1983) A Global Measure of Perceived Stress. Journal of Health and Social Behavior, 24, 385-396. https://doi.org/10.2307/2136404

[6] Moghaddam, B., Jackson, M. (2004). Effect of Stress on Prefrontal Cortex Function. Neurotoxicity Research, 6, 73-78. https://doi.org/10.1007/BF03033299

[7] Wang, J., Rao, H., Wetmore, G.S., Furlan, P.M., Korczykowski, M., Dinges, D.F. and Detre, J.A. (2005) Perfusion Functional MRI Reveals Cerebral Blood Flow Pattern under Psychological Stress. Proceedings of the National Academy of Sciences of the United States of America, 102, 17804-17809. https://doi.org/10.1073/pnas.0503082102

[8] Holmes, T.H. and Rahe, R.H. (1967) The Social Readjustment Rating Scale. Journal of Psychosomatic Research, 11, 213-218. https://doi.org/10.1016/0022-3999(67)90010-4

[9] Simonson, E., Baker, C., Burns, N., Keiper, C., Schmitt, O.H. and Stackhouse, S. (1968) Cardiovascular Stress (Electrocardiographic Changes) Produced by Driving an Automobile. American Heart Journal, 75,125-135. https://doi.org/10.1016/0002-8703(68)90123-3

[10] Tomei, F., Fantini, S., Tomao, E., Baccolo, T.P. and Rosati, M.V. (2000) Hypertension and Chronic Exposure to Noise. Archives of Environmental Health, 55, 319-325. https://doi.org/10.1080/00039890009604023

[11] Babisch, W., Ising, H., Gallacher, J.E., Sweetnam, P.M. and Elwood, P.C. (1999) Traffic Noise and Cardiovascular Risk: The Caerphilly and Speedwell Studies, Third Phase-10-Year Follow Up. Archives of Environmental Health, 54, 210-216. https://doi.org/10.1080/00039899909602261

[12] Soulairac, A. (1992) Le bruit: Aspects neuro-endocriniens. Bulletin de L'Académie Nationale de Médecine, 176, 401-405.

[13] Mouret, J. and Vallet, M. (1998) Les effets du bruit sur la santé, ministère de l’Emploi et de la Solidarité. Comelli, Paris.

[14] Muzet, A. and Ehrhart, J. (1980) Habituation of Heart Rate and Finger Pulse Responses to Noise during Sleep. In: Tobias, J.V., Ed., Noise as a Public Health Problem, ASHA Report, Rockville, Vol. 10, 401-413. 
[15] Vallet, M., Gagneux, J.M., Clairet, J.M., et al. (1983) Heart Rate Reactivity to Aircraft Noise after a Long Term Exposure. In: Rossi, G., Ed., Noise as a Public Health Problem, Centro Ricerche e Studi Amplifon, Milano, 965-971.

[16] Dalziel, J.R. and Soames Job, R.F. (1997) Motor Vehicle Accidents, Fatigue and Optimism Bias in Taxi Drivers. Accident Analysis and Prevention, 29, 489-494.

[17] Rosenbloom, T. and Shahar, A. (2007) Differences between Taxi and Nonprofessional Male Drivers in Attitudes toward Traffic Violation Penalties. Transportation Research Part F: Traffic Psychology and Behaviour, 10, 428-435.

[18] Machin, M.A. and De Souza, J.M.D. (2004) Predicting Health Outcomes and Safety Behaviour in Taxi Drivers. Transportation Research Part F: Traffic Psychology and Behaviour, 7, 257-270.

[19] Burns, P.C. and Wilde, G.J.S. (1995) Risk Taking in Male Taxi Drivers: Relationships among Personality, Observational Data and Driver Records. Personality and Individual Differences, 18, 267-278.

[20] Mottier, C. (2013) Psychologue, Sélection \& Conseils, Nyon, Suisse 9. https://www.selectionetconseils.ch

[21] Wallon, P. and Mesmin, C. (2009) Test de la figure complexe de Rey. ECPA, Paris.

[22] Cohen, S. and Janicki-Deverts, D. (2012) Who's Stressed? Distributions of Psychological Stress in the United States in Probability Samples from 1983, 2006, and 2009. Journal of Applied Social Psychology, 42, 1320-1334. https://doi.org/10.1111/j.1559-1816.2012.00900.x

[23] Quintard, B. (1994) Du Stress objectif au stress perçu. In: Bruchon-Schweitzer, M. and Dantzer, R., Eds., Introduction à la psychologie de la santé, Collection psychologie d aujourd'hui, Presses Universitaires de France, Paris, 43-66, 220 p.

[24] Peltzer, K. (2003) Superstition, Risk-Taking and Risk Perception of Accidents among South African Taxi Drivers. Accident Analysis \& Prevention, 35, 619-623.

[25] Brosset, N. and Muller, B. (1999) Agent de maîtrise et réorganisation du travail de production. Archives des Maladies Professionnelles et de P Environnement, 60, 579.

[26] Nakano, Y., Nakamura, S., Hirata, M., Harada, K., et al. (1998) Immune Function and Life Style of Taxi Drivers in Japan. Industrial Health, 36, 32-39. https://doi.org/10.2486/indhealth.36.32

[27] Comité National de Prévention des Accidents de la Circulation (1999) Seul le détail pour 1999 est disponible au CNPAC. Concernant 2000 et 2001, les études et analyses sont lancées.

[28] Coblentz, A.M. and Cabon, P. (1994) Effets de la monotonie et de l'organisation des horaires de travail sur la vigilance et la performance des opérateurs. Encycl Med Chir (Paris, France), Toxicologie, Pathologie professionnelle, 16-784-A10, 8 p.

[29] Chamoux, A., Paris, C., Desheulles, J., et al. (1999) Stress et travail: Rôle de la pénibilité psychique du travail. Archives des Maladies Professionnelles et de P Environnement, 60, 570-573.

[30] Willams, E.S., et al. (2000) The Effects of Job Satisfaction and Perceived Stress on Physical and Mental Health and Withdraw Intentions of Physicians. Academy Management of Proceedings.

[31] Chang, E.C. (1998) Does Dispositional Optimism Moderate the Relation between Perceived Stress and Psychological Well-Being? A Preliminary Investigation. Personalitiy and Indivial Differences, 25, 233-240.

[32] Vezina, M. (1990-1999) Organisation du travail et santé mentale: Etat des connaissances et perspectives d'intervention. Revue de Médecine du Travail, 26, 14-22. 